\title{
Histiocitose de Langerhans no Adulto: Experiência de Dois Hospitais Portugueses
}

\author{
Adulthood Langerhans Cell Histiocytosis: Experience of Two Portuguese \\ Hospitals
}

Margarida Dantas de BRITO1, Ângelo MARTINS'1, Joaquim ANDRADE², José GUIMARÃES², José MARIZ1

Acta Med Port 2014 Nov-Dec;27(6):726-730

RESUMO

Introdução: A histiocitose de células de Langerhans é uma doença heterogénea e mais frequente em crianças. Entre 1/2001 e 12/2013 admitimos 20 doentes com HCL nas duas instituições. O objectivo deste trabalho foi caracterizar esta população, avaliando as formas de apresentação, o estadiamento e tratamento.

Material e Métodos: Estudo retrospectivo; consulta do processo clínico.

Resultados: Dos 16 doentes analisáveis verificamos uma mediana de idade 34 anos (15-48), 10 mulheres e 6 homens. Os motivos que determinaram a referenciação dos doentes foram: queixas respiratórias em 37,5\%; alterações ósseas em 37,5\%; queixas dentárias em 25\%; sintomas constitucionais em 19\%; lesões mucocutâneas em $6 \%$ e outro foi um achado histológico inesperado após tiroidectomia. O diagnóstico histológico foi obtido em: osso em $50 \%$; pulmão em $37,5 \%$; fígado, mucosa vulvar e peça de tiroidectomia em $6 \%$, respectivamente. O estadiamento assumido na prática clínica foi: envolvimento de órgão único (uni/multifocal) em $69 \%$ e doença multissistémica em $31 \%$. A mediana de seguimento foi cinco anos (dois meses-11 anos) e a sobrevivência global $92 \%$. Actualmente: $19 \%$ estão vivos sem doença; $44 \%$ estão vivos com doença; $25 \%$ estão em tratamento e $12 \%$ morreram.

Discussão: Estes resultados estão de acordo com a literatura. No entanto, segundo as recomendações actuais consideramos que $56 \%$ doentes efectuaram estudo complementar incompleto condicionando subestadiamento e provavelmente subtratamento. Verificase heterogeneidade de procedimentos no estadiamento e tratamento.

Conclusão: Frequentemente há dificuldades e atraso no diagnóstico desta entidade clínica. São importantes estudos prospectivos internacionais na população adulta.

Palavras-chave: Adulto; Histiocitose de Células de Langerhans.

\section{ABSTRACT}

Introduction: Langerhans cell histiocytosis is a heterogeneous disease, more frequently diagnosed during childhood. Between 1/2001 and 12/2013, 20 adult patients were admitted at both Hospitals. This work aimed at characterizing this population.

Material and Methods: Retrospective study, review of clinical records.

Results: 16 patients were eligible to analysis. The median age at diagnosis was 34 years (15-48); 10 males and 6 females. The referral motive was: respiratory complaints $-37.5 \%$; bone changes $-37.5 \%$; dental complaints $-25 \%$; constitutional symptoms - $19 \%$; mucocutaneous lesions $-6 \%$ and one patient $(6 \%)$ was accidentally diagnosed after a thyroidectomy. The tissue of histological diagnosis was: bone $-50 \%$; pulmonary tissue $-37.5 \%$; liver, genital mucosa and thyroid - $6 \%$, respectively. Staging was: single organ involvement (uni/multifocal) - $69 \%$ and multisystem disease in $31 \%$. Clinical re-evaluation of these cases is being done at the moment. The median follow up was 5 years ( 1 month - 11 years) and the overall survival was $92 \%$. Currently $19 \%$ are alive without signs of disease; $44 \%$ are alive with disease; $25 \%$ are under treatment and $12 \%$ died.

Discussion: These results agree with published literature. Considering the actual guidelines $56 \%$ patients were incompletely staged, which probably lead to suboptimal treatment. There is heterogeneity of clinical procedures aiming at staging and treatment of these patients.

Conclusion: The diagnosis of adulthood Langerhans cell histiocytosis is difficult considering the diversity of clinical behavior. Frequently this also leads to diagnosis delay. Prospective international clinical trials enrolling adult patients are important.

Keywords: Adult; Histiocytosis, Langerhans-Cell.

\section{INTRODUÇÃO}

A histiocitose de células de Langerhans (HCL) é uma doença rara e heterogénea, o que justifica a escassez de conhecimento em relação à sua etiologia, evolução clínica e tratamento. Até à data não está determinado se tem por base um distúrbio imunológico ou neoplásico. No entanto sabe-se que é um distúrbio clonal e recentemente foi identificada uma mutação no gene BRAF (BRAFV600E), presente em mais de metade dos casos. Estes dados favorecem mais a hipótese de origem neoplásica. ${ }^{1-3}$

São células de provável linhagem mielóide e o seu imunofenótipo caracteriza-se por positividade dos antigénios:
CD10, proteína S-100, CD207 e CD1a., ${ }^{1,2}$ Presume-se que tem origem nas células dendríticas de Langerhans, habitualmente residentes na epiderme e envolvidas na apresentação de antigénios, mantendo uma estreita relação com os linfócitos T. Contudo, alguns autores referem que estas células podem ter origem em monócitos plasmocitóides circulantes. ${ }^{3,4}$

A HCL tem uma incidência estimada de 1 a 2 casos/ milhão/ ano nos adultos e 3 a 5 casos/milhão/ano nas crianças. Uma vez que é mais frequente em idade pediátrica muitas recomendações para orientação dos doentes

1. Serviço de Onco-hematologia. Instituto Português de Oncologia. Porto. Portugal.

2. Serviço Hematologia. Hospital de São João. Porto. Portugal.

Recebido: 19 de Março de 2014 - Aceite: 07 de Julho de 2014 | Copyright @ Ordem dos Médicos 2014 
adultos têm por base os protocolos desenvolvidos para tratamento das crianças. ${ }^{1,2}$

A apresentação clínica é muito heterogénea, podendo envolver qualquer órgão ou sistema. Destacamos o envolvimento ósseo porque é a forma de apresentação mais comum, tanto no adulto como na criança. Geralmente segue um padrão unifocal no adulto e multifocal em crianças e apresenta-se como lesão osteolítica (o aspecto de esclerose relaciona-se com o início do processo de resolução). Pode afectar, por ordem de frequência, os ossos do crânio, fémur, órbita, costelas, mandíbula, maxilar (Fig. 1) e vértebras. ${ }^{1-4}$

O sistema nervoso central geralmente é envolvimento por contiguidade a partir de lesões nos ossos do crânio e verifica-se uma predileção pelo cerebelo, núcleos hipotalâmicos e pituitária causando diabetes insípida. A infiltração pelas células de Langerhans raramente causa efeito de massa sendo, por isso, difícil de visualizar em tomografia computorizada. ${ }^{1-4}$

As lesões cutâneas estão em $40 \%$ dos casos associadas a doença multissistémica, pelo que a sua presença deve suscitar investigação de outros locais de envolvimento. ${ }^{1}$

A HCL pulmonar isolada é considerada uma entidade distinta, relaciona-se com tabagismo e habitualmente surge em doentes jovens. Radiologicamente há um padrão típico micronodular, de predomínio nos lobos superiores e peri-hilar, poupando os ângulos costo-frénicos (Fig. 2). A tomografia computorizada revela um padrão em favo de mel (Fig. 3). O envolvimento pulmonar não é frequente na doença disseminada. ${ }^{1-4}$

Segundo as recomendações atuais o envolvimento de órgãos de risco define-se por doença afectando o baço, fígado, medula óssea e pulmão (excluindo o envolvimento pulmonar isolado). Alguns autores também consideram o envolvimento de locais de risco especial referindo-se por esta designação os locais anatómicos com risco de desfiguração, perda de função de órgão ou envolvimento do sistema nervoso central. ${ }^{1-4}$

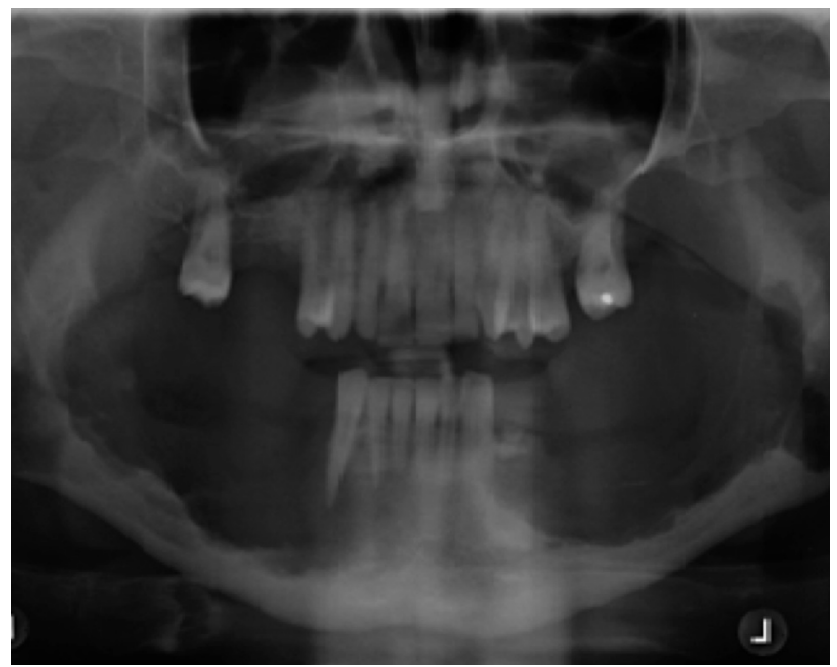

Figura 1 - Ortopantomografia de doente com HCL com envolvimento ósseo da mandíbula. Observa-se perda significativa de massa óssea e múltiplas peças dentárias.
Estão descritas diferentes estratégias terapêuticas em função do estadiamento. No caso de doença localizada, nomeadamente doença óssea unifocal, destacamos como opção terapêutica de primeira linha a curetagem cirúrgica, a corticoterapia intralesional ou a radioterapia local. Quando há doença multissistémica ou envolvimento de órgãos de risco está indicado tratamento sistémico com quimioterapia (vimblastina e prednisolona ou cladribina, entre outros). ${ }^{5-11}$

O objectivo deste trabalho foi caracterizar a população de doentes adultos com HCL, diagnosticada e tratada em dois centros hospitalares - Instituto Português de Oncologia e Hospital de São João (IPO e HSJ), Porto. Pretendemos avaliar as suas características demográficas e clínicas, o tratamento efectuado, as respostas obtidas, bem como a sobrevivência global.

\section{MATERIAL E MÉTODOS}

Estudo longitudinal retrospectivo, envolvendo a população de doentes com HCL diagnosticados e tratados no IPO e HSJ entre Janeiro 2001 e Junho 2013. O método de recolha de dados teve por base a consulta do processo clínico único e informático e recolha de dados clínicos retrospectivos. Análise estatística com recurso ao software SPSS v13.0 e análise de sobrevivência de acordo com o método Kaplan-Meier.

\section{RESULTADOS}

Identificámos 20 doentes com este diagnóstico nas duas instituições, ao longo de um período de 12 anos. Excluímos da análise global quatro doentes: três por ausência de dados clínicos e um por ter sido diagnosticado na infância. Entre os doentes analisáveis, 10 eram de sexo feminino e seis de sexo masculino. A mediana de idade foi de 34 anos (15-48) e a maioria tinha hábitos tabágicos $(69 \%-11$ doentes).

$\mathrm{Na}$ data da observação inicial foram registadas: queixas respiratórias (pneumotórax, tosse persistente, achado imagiológico) em $37,5 \%$ (seis doentes); alterações ósseas

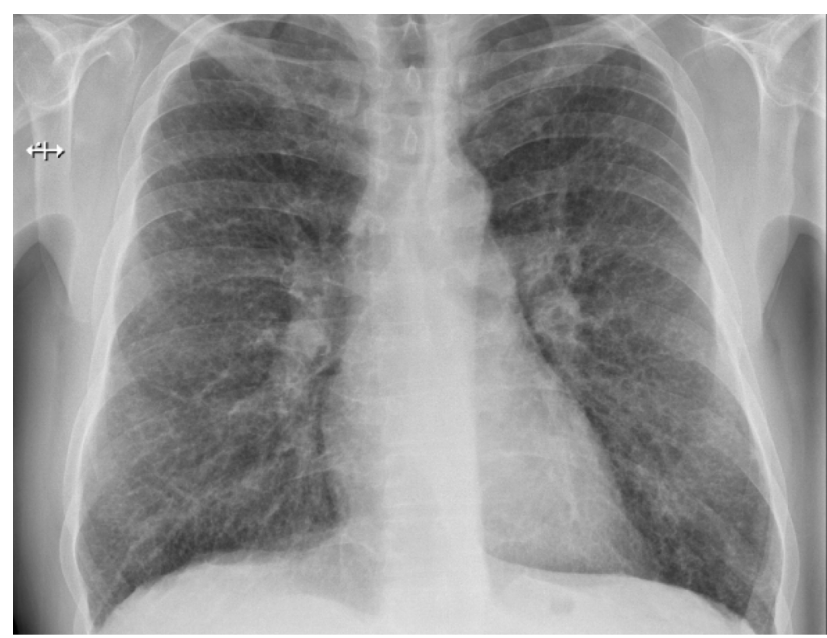

Figura 2 - Radiografia do tórax de doente com HCL com envolvimento pulmonar. Verifica-se um padrão micro-nodular, predominantemente nos lobos superiores e região peri-hilar, poupando os ângulos costo-frénicos. 


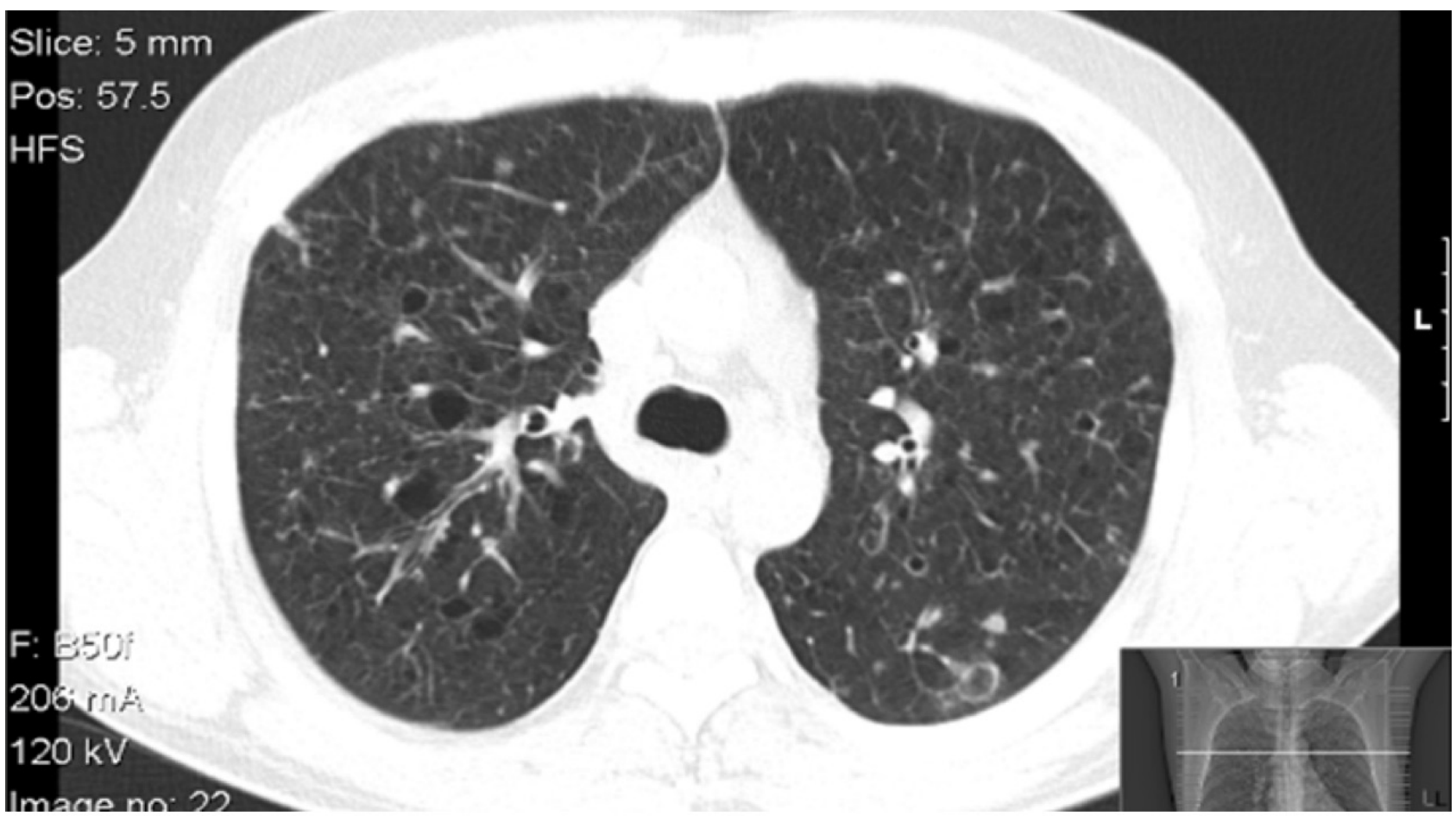

Figura 3 - Tomografia computorizada de um doente com HCL com envolvimento pulmonar. A imagem revela um padrão em favo de mel.

(dor, dismorfia) em 37,5 (seis doentes); queixas dentárias (odontalgia, mobilidade, perda espontânea de dentes) em $25 \%$ (quatro doentes); sintomas constitucionais em $19 \%$ (três doentes); lesões muco-cutâneas em um doente; enquanto noutro doente se tratou de um achado histológico inesperado em peça de tiroidectomia, concomitantemente com carcinoma papilar da tiroide (Tabela 1).

O serviço de referenciação destes doentes foi: $56 \%$ (nove doentes) Hematologia; 32\% (cinco doentes) Pneumologia; 6\% (um doente) Endocrinologia; 6\% (um doente) Dermatologia.

Entre o início das queixas e o estabelecimento do diagnóstico verificamos uma mediana de cinco meses (duas semanas - oito anos). Durante o estudo do quadro clínico inaugural $19 \%$ (três doentes) desenvolveram queixas compatíveis com envolvimento/ progressão no sistema nervoso central.

Em 15 doentes obtivemos um diagnóstico definitivo (histológico) e um doente iniciou tratamento com diag-

Tabela 1 - Heterogeneidade das manifestações clínicas em doentes com HCL

\begin{tabular}{lc}
\hline Motivo de referenciação & Incidência (\%) \\
\hline Queixas respiratórias & $37,5 \%$ \\
Alterações ósseas & $37,5 \%$ \\
Queixas dentárias & $25 \%$ \\
Sintomas constitucionais & $19 \%$ \\
Lesões muco-cutâneas & $6 \%$ \\
Achado histológico-tiroidectomia & $6 \%$ \\
\hline
\end{tabular}

nóstico presuntivo (clínica altamente sugestiva e múltiplas biópsias inconclusivas). O órgão de diagnóstico histológico foi: osso em $50 \%$ (oito doentes); pulmão em $37,5 \%$ (dois doentes); fígado; mucosa vulvar e peça de tiroidectomia $6 \%$ (um doente), respectivamente. Dos doentes com envolvimento pulmonar, cinco efectuaram lavado-broncoalveolar e apenas um teve critérios de diagnóstico, necessitando os restantes de efectuar biópsia pulmonar.

O estadiamento considerado foi: envolvimento de órgão único (uni/multifocal) em 69\% (11 doentes) e doença multissistémica em $31 \%$ (cinco doentes). Nesta série 25\% (quatro doentes) tinham envolvimento de órgãos de risco - $19 \%$ (três doentes) envolvimento pulmonar concomitante com outros órgãos e $6 \%$ (um doente) fígado. Como referido, nesta série 19\% (três doentes) apresentaram envolvimento do sistema nervoso central, sob a forma de diabetes insípida (um destes apresentou concomitantemente manifestações graves de psicose orgânica) e 19\% (três doentes) apresentavam envolvimento ósseo de risco especial - vértebras, mandíbula e ossos do crânio.

Segundo as recomendações actuais consideramos que $56 \%$ (nove doentes) efectuaram estudo complementar incompleto à data do diagnóstico, o que provavelmente resultou em subestadiamento / subtratamento.

$\mathrm{Na}$ Tabela 2 apresentamos as opções terapêuticas efectuadas como tratamento de primeira linha.

A mediana de seguimento foi de cinco anos (dois meses - 11 anos) e a sobrevivência global 92\% ( $\pm 0,7 \%$ ). Actualmente: $19 \%$ (três doentes) estão vivos sem doença; $44 \%$ (sete doentes) estão vivos com doença; $25 \%$ (quatro doentes) estão em tratamento e 12\% (dois doentes) morreram (um por descompensação de diabetes insípida; outro por Linfoma não Hodgkin de células $T$ periféricas, 
Tabela 2 - Opção terapêutica de acordo com estadiamento

\begin{tabular}{lcc}
\hline Opção Terapêutica & $\begin{array}{c}\text { Unissistémico } \\
\%,(\boldsymbol{n})\end{array}$ & $\begin{array}{c}\text { Multissistémico } \\
\%(\boldsymbol{n})\end{array}$ \\
\hline Vigilância & $19 \%(3)$ & $6 \%(1)$ \\
Cirurgia +/- Radioterapia & $19 \%(3)$ & $6 \%(1)$ \\
Corticoterapia & $19 \%(3)$ & $6 \%(1)$ \\
Vimblastina + Prednisolona & $12,5 \%(2)$ & - \\
Vimblastina + Prednisolona + Etoposídeo & - & $12,5 \%(2)$ \\
\hline
\end{tabular}

Tabela 3 - Recomendações para o estadiamento, adaptado de guidelines da Histyocite Society

Exames complementares de diagnóstico recomendados para estadiamento

Iniciais Adicionais - quadros clínicos específicos

Hemograma

Bioquímica com função renal, electrólitos, função hepática, proteínas totais, albumina, ferritina.

Estudo sumário da coagulação

Osmolaridade urinária/densidade urinária

Ecografia abdominal

Radiografia tórax

Radiografia do esqueleto e/ou Cintilograma ósseo
Mielograma e biópsia óssea

(citopenias persistentes inexplicadas)

Biópsia hepática (se disfunção hepática e apenas se clinicamente relevante)

Broncofibroscopia com lavado bronco-alveolar (se Tomografia computorizada pulmonar mostrar envolvimento mas sem padrão típico, para diagnostico diferencial)

Ressonância magnética crânio (se queixas neurológicas ou visuais, lesões ósseas craniofaciais para esclarecimento de invasão/caracterização da extensão)

Ressonância magnética da coluna vertebral (excluir compressão na presença de lesões vertebrais suspeitas)

Avaliação por otorrinolaringologia/

Tomografia computorizada alta resolução/

Ressonância magnética

(alterações auditivas, avaliação de envolvimento da mastóide)

Estudo endoscópico com biópsias

(diarreia persistente e inexplicada, sintomas de mal-absorção) diagnosticado após duas linhas terapêuticas para HCL).

É de referir que um doente foi referenciado para transplantação de progenitores hematopoiéticos. No entanto, foi excluído da análise global por ter sido diagnosticado na infância. Apresentava doença óssea multifocal e diabetes insípida, teve múltiplas recidivas e várias linhas de tratamento no serviço de Pediatria. Após a maioridade foi transferido para o serviço de Hematologia, tendo efectuado quimioterapia com cladribina e transplante alogénico de progenitores hematopoiéticos de dador não aparentado. Actualmente está vivo, sem evidência de doença e com um seguimento clínico de 23 anos.

\section{DISCUSSÃO}

Globalmente os resultados encontrados enquadram-se com o que está descrito na literatura internacional.

A diversidade de serviços hospitalares de referenciação relaciona-se com a grande heterogeneidade de manifestações clínicas inaugurais e potencial envolvimento de qualquer órgão/sistema..$^{1-3}$ Assim, apesar de ser uma entidade rara, torna-se importante que as diversas especialidades médicas estejam conscientes desta patologia no adulto, tanto mais que afecta predominantemente indivíduos jovens. O diagnóstico requer alto grau de suspeição e o seu estabelecimento definitivo tem por base o exame anatomo- 
-patológico das lesões e não raras vezes são necessárias várias biópsias até se conseguir um exame histológico conclusivo. ${ }^{1-3} \mathrm{O}$ exame citológico de uma amostra de lavado-broncoalveolar está descrito na literatura (critério de positividade se maior de $5 \%$ células CD1a+ em não fumadores) no entanto, na nossa série, este exame foi pouco útil para o diagnóstico, uma vez que dos cinco doentes que o efectuaram apenas um teve critérios de positividade. ${ }^{1}$

Relativamente ao estadiamento e face às recomendações actuais consideramos que um grupo de doentes foi subestadiado e consequentemente subtratado. ${ }^{1-4} \mathrm{Na}$ maioria dos doentes não se verificou avaliação da osmolaridade urinária, nove doentes não efectuaram estadiamento ósseo nem avaliação imagiológica abdominal e dois doentes apresentaram queixas dentárias durante quadro inaugural não investigadas. No entanto, é de salientar que estas recomendações são recentes e não estavam disponíveis à data do diagnóstico inaugural da maioria destes doentes. Está em curso reapreciação clínica destes casos, nomeadamente reestadiamento e ponderação da necessidade de alterar a estratégia terapêutica. Os exames complementares recomendados para o estadiamento estão especificados na tabela 3. ${ }^{1,2}$

O tratamento efectuado está de acordo com as opções descritas na literatura, podendo variar desde curetagem cirúrgica na lesão óssea unifocal até quimioterapia e transplante de progenitores hematopoiéticos na doença multissistémica recidivante ou refractária. ${ }^{2-5,10,11}$ Todavia são raros

\section{REFERÊNCIAS}

1. Girschikofsky M, Arico M, Castillo D, Chu A, Doberauer C, Fichter J, et al. Management of adult patients with Langerhans cell histiocytosis: recommendations from an expert panel on behalf of Euro-Histio-Net. Orphanet J Rare Dis. 2013;8:72.

2. Howarth DM, Gilchrist GS, Mullan BP, Wiseman GA, Edmonson JH, Schomberg PJ, et al. Langerhans cell histiocytosis, diagnosis, natural history, management, and outcome. Cancer. 1999;85:2278-90.

3. Gayane B, Adalian V, Vergilio J, Fleming M, Rollins B. Pathogenesis of Langerhans cell histiocytosis. Ann Rev Pathol Mech Dis. 2013;8:1-20.

4. Oussama A, Maarten E, Weitzman S. Langerhans cell histiocytosis: Current concepts and treatments. Cancer Treat Rev. 2010;36:354-9.

5. Giona F, Caruso R, Testi A, Moleti M, Malagnino F, Maurizio M. Langerhans cell histiocytosis in adults. A clinical and therapeutic analysis of 11 patients from a single institution. Cancer. 1997;80:1786-91.

6. Weitzman S, Wayne AS, Arceci R, Lipton JM, Whitlock JA. Nucleoside analogues in the therapy of Langerhans cell histiocytosis: a survey of members of the histiocyte society and review of the literature. Med Pediatr Oncol. 1999;33:476-81.

7. Bernard F, Thomas C, Bertrand Y, Munzer M, Landman Parker J, Ouache $\mathrm{M}$, et al. Multi-centre pilot study of 2-chlorodeoxyadenosine and cytosine arabinoside combined chemotherapy in refractory Langerhans cell histiocytosis with haematological dysfunction. Eur $\mathrm{J}$ Cancer. ensaios clínicos randomizados para a população adulta, que fundamentem estas ou outras opções terapêuticas. Por este motivo destacamos os ensaios clínicos desenvolvidos pela Histiocyte Society e sugerimos a adopção das recomendações desta sociedade para orientar o tratamento destes doentes. ${ }^{2}$

\section{CONCLUSÃO}

Esta análise retrospectiva ilustra a diversidade do comportamento clínico desta doença, o que condiciona dificuldade e atraso no diagnóstico. Verifica-se heterogeneidade de procedimentos no estadiamento e tratamento destes doentes, pelo que se salienta a necessidade e importância de estudos prospectivos, randomizados e multicêntricos envolvendo doentes adultos, atendendo à baixa incidência desta patologia nesta faixa etária.

\section{OBSERVAÇÕES}

Apresentado como poster na reunião anual da Sociedade Portuguesa Hematologia. Porto. 2013.

\section{CONFLITO DE INTERESSES}

Os autores declaram não haver nenhum conflito de interesses relativamente ao presente artigo.

\section{FONTES DE FINANCIAMENTO}

Os autores declaram não haver nenhuma fonte externa de financiamento para a realização deste artigo

8. Steiner M, Matthes-Martin S, Attarbaschi A, Minkov M, Grois N, Unger $\mathrm{E}$, et al. Improved outcome of treatment-resistant high-risk Langerhans cell histiocytosis after allogeneic stem cell transplantation with reducedintensity conditioning. Bone Marrow Transplant. 2005;36:215-25.

9. Stine KC, Saylors RL, Williams LL, Becton DL. 2-Chlorodeoxyadenosine for the treatment of refractory or recurrent Langerhans cell histiocytosis in pediatric patients. Med Pediatr Oncol. 1997;29:288-92.

10. Grau J, Ribera JM, Tormo M, Indiano JM, Vercher J, Sandoval V, et al. Results of treatment with 2-chlorodeoxyadenosine in refractory or relapsed Langerhans cell histiocytosis. Study of 9 patients. Med Clin. 2001;116:339-42.

11. Morgan $\mathrm{G}$. Myeloablative therapy and bone marrow transplantation for Langerhans cell histiocytosis. Br J Cancer. 1994;23:S52-3.

12. Greinix HT, Storb R, Sanders JE, Petersen FB. Marrow transplantation for treatment of multisystem progressive Langerhans cell histiocytosis. Bone Marrow Transplant. 1992;10:39-44.

13. Akkari V, Donadieu J, Piguet C, Bordigoni P, Michel G, Blanche S, et al, Hematopoietic stem cell transplantation in patients with severe Langerhans cell histiocytosis and hematological dysfunction: experience of the French Langerhans Cell Study Group. Bone Marrow Transplant. $1999 ; 24: 935-8$. 


\section{Histiocitose de Langerhans no Adulto: Experiência de Dois Hospitais Portugueses}

Acta Med Port 2014:27:726-730

Publicado pela Acta Médica Portuguesa, a Revista Científica da Ordem dos Médicos

Av. Almirante Gago Coutinho, 151

1749-084 Lisboa, Portugal.

Tel: +351218428215

E-mail: submissao@actamedicaportuguesa.com

www.actamedicaportuguesa.com

ISSN:0870-399X | e-ISSN: 1646-0758

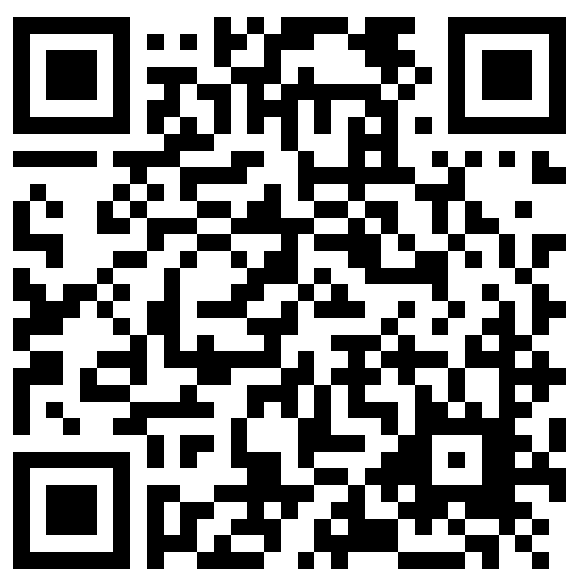

